\title{
Impact of Vibration on Double-Porosity Unsaturated Laterite Soil with Different Water Contents
}

\author{
Mohd Fadhli Abd Rashid ${ }^{1}$, Noraliani Alias ${ }^{1,}$, , Kamarudin Ahmad ${ }^{2}$, Radzuan Sa'ari ${ }^{1}$, Mohd Zamri Ramli ${ }^{3}$ and Zulkiflee \\ Ibrahim $^{1}$ \\ ${ }^{1}$ Department of Water and Environmental Engineering, School of Civil Engineering, Faculty of Engineering, Universiti Teknologi \\ Malaysia, 81310 Johor Bahru, Johor, Malaysia \\ ${ }^{2}$ Department of Geotechnics and Transportation, School of Civil Engineering, Faculty of Engineering, Universiti Teknologi Malaysia, \\ 81310 Johor Bahru, Johor, Malaysia \\ ${ }^{3}$ Institute of Noise and Vibration, School of Civil Engineering, Faculty of Engineering, Universiti Teknologi Malaysia, 81310 Johor \\ Bahru, Johor, Malaysia
}

\begin{abstract}
Engineering practices, natural and man-made vibrations phenomena such as blasting, construction machinery and operations, and vehicle traffic vibrations can cause stresses to soils. In addition, changes in moisture content may affect the speed of liquid penetrating the soils. Therefore, the impacts due to vibrations and changes in moisture contents need to be addressed to ensure geo-environment sustainability. This can be achieved by conducting laboratory experiments to determine the behaviour of deformable double-porosity soil samples with different water contents subjected to non-repeated vibrations. In this study, aggregated laterite soil samples were prepared with $30 \%$ and $34 \%$ moisture contents. Each aggregated soil was poured into an acrylic column then the soil was compressed to a pre-determined height of $10 \mathrm{~cm}$. Testing was performed on each soil column using a vibrating table where accelerometers were installed to measure high-frequency acceleration time histories on the surfaces of the vibrating table and laterite soil. The tests were conducted by increasing the amplitude of displacement and the acceleration time histories were collected to record maximum amplitudes. The results showed that the soil surface acceleration in non-repeated vibration was increased with increasing moisture contents. It was also discovered that the speed of liquid penetration was influenced by vibration due to rearrangement of soil particles and changes in soil structure and porosity characteristics.
\end{abstract}

\section{Introduction}

Natural and man-made phenomena can cause dynamic stress to be imposed on soils; such as was experienced during the earthquake events that were reported in Ranau and Tawau, Sabah, Malaysia [1-2]. Figure 1 displays the ground failure effect after an earthquake hit Ranau, Sabah. The after effects of earthquakes result in volumetric deformation of soil aggregate structures, soil macro structure rearrangements, unstable soil structure conditions as well as cracked soil ${ }^{3}$. All of these alterations ultimately affect the condition and characteristics of pore sizes. Earthquake incidents have caused damage and leakages to underground drainage pipes and liquid tanks [1-2].

Therefore, the vibration and seepage of liquids in the ground soil is a problem that requires major emphasis and attention to ensure the sustainability of the geoenvironment. The fractured soil reduces the intact soils' shear strength and increases hydraulic conductivity ${ }^{4}$. The speed and pattern of fluid migration is ultimately affected by soil structure. According to existing research by ${ }^{5}$ it has been recognised that cracked soil plays an influential role towards the flow of water that goes through problematic soil. Similarly, ${ }^{4}$ has identified the significant changes of mechanical properties and the hydrological behaviour found in fractured porous media. Soil that displays two specific scales of porosity media is known as double porosity media ${ }^{6}$.

In the practice of engineering, natural and man-made occurrences can be the triggering factor that imposes dynamic stress to be put on soils. These phenomena include earthquakes, wind and wave loading, vehicle traffic vibrations and blasting and construction operations ${ }^{7}$. A soils' strength behaviour during vibration does not only depend on the physical properties of the soil such as cohesion, internal friction angle, mineralogy soil particles, density, grain size distribution, void ratio or dry density, and moisture content, but also on characteristics of vibration such as amplitude, acceleration and frequency .

The researchers have recognized that the prevalent problem of gathering reliable data on the movement behaviour of immiscible fluid and the physical

Corresponding author: noraliani@utm.my 
laboratory is to understand, observe, monitor and solve such issues. Accelerometer response analysis has been applied to identify the dis-amplification or amplification shaking process in the soil sample. So, there is a need to explore the deformation behaviour of soil media due to vibration attempts in order to bridge the research gap. It is important to determine the physical phenomena of deformable double-porosity and take into consideration the different moisture contents and different vibration amplitude methods in soil.

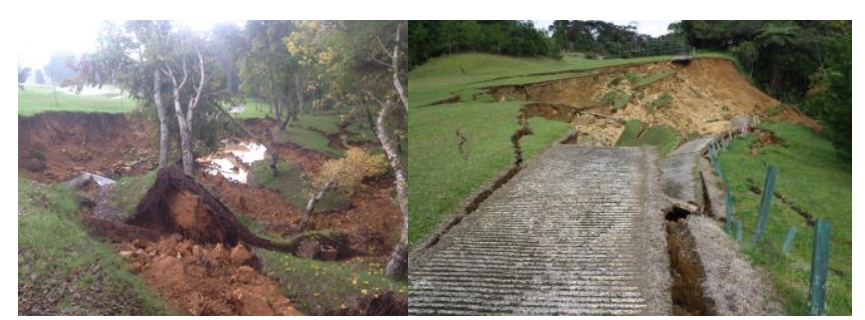

Fig. 1. Ground failure after earthquake in Ranau, Sabah

\section{Experimental theory}

Soil structure is affected by earthquake vibrations and moisture content. It is acknowledged that soils display a range of different structures at different scales, and that soils are not completely homogeneous in character. According to ${ }^{6}$, double-porosity media (in usual conditions termed as "soil") display two specific scales of porous media. Double-porosity media is characterized using different hydraulic properties and pore sizes with two specific sub-regions in soil ${ }^{8}$. The soils with intra and inter-aggregate pores for aggregated innate soil display pore-size bimodal distribution that can be found in compacted soils and agricultural topsoil [8-9] Additionally, ${ }^{11}$ discovered that soil in laboratory can be used to create double-porosity characteristics which are performed under constant pressure head, initially with double-porosity for one-dimensional infiltration experiments.

Generally, in earthquake engineering, laboratory equipment has been utilized to evaluate structures or ground responses. The bedrock motion with highest response is called Peak Ground Acceleration (PGA) whereas the free surface motion with highest response is called the Peak Surface Acceleration (PSA). If the value of PSA is higher than PGA, this demonstrates amplification. Contrarily, if the value of PGA is higher than PSA, this demonstrates dis-amplification. For this study, ground response analysis was adopted to model the acceleration responses on the soil sample by the propagation of ground motion to the surface. This analysis was chosen because, in practice, the ground response analysis is often used to determine the crack and amplification of the response. Moreover, for this laboratory study, the terms PGA and PSA were changed to more suitable names to better reflect on the experiment conditions, and were renamed as Peak Table Acceleration (PTA) and Peak Specimen Surface Acceleration (PSSA).
The deformation of double-porosity soil is due to vibration effects, which, according to ${ }^{12}$ is defined as strong earthquake shakes that meet with water-saturated granular soils such as soil and sand may liquefy and cause deformations, bringing along with it great destructive power. ${ }^{12}$ had also demonstrated using the principle analysis, that liquefaction is not a rigidly undrained process, but it is in fact the grain rearrangement, fluid movement and changes in permeability which lead to strength loss in soil structure. Furthermore, formations of fractured porosity are characterized by water-bearing formations, while a fracture is created from a break of the rock masses caused by tectonic force 13 . Computational and numerical methods in the past decades were mainly used in studies of double-porosity media, where most researchers such as [7], [13-17]used fractured rock as their media. However, as these previous researchers had mainly used numerical models for the study of double-porosity soil media, real physical experiments were performed less often.

Recently, the physical experimental methods on double-porosity soil have begun to be used by researchers such as [7], [18-20]. Actual physical experiments are very challenging to perform inside the laboratory, especially due to the reasons that large fractured rock is hard to find and the process of relocating actual samples from the site to the laboratory is very complicated and accumulates high costs to execute. There is also a shortage of necessary equipment as only a few pieces of equipment are available to carry out the physical experiments.

Previous experiments have mentioned about doubleporosity media and this has contributed to a deeper understanding of soil behaviour in the double-porosity form. These mentioned experiments were limited to common aggregated method and numerical model in double-porosity soil, however there was no application or vibration effects tested on the soil samples. To the best of our knowledge and from having reviewed other research papers, it can be seen that there is a research gap to be observed and identified with regards to laboratory experiments on crack double-porosity soil under vibration effect. Essentially, this study covers the physical laboratory experiment model where aggregated soil samples are vibrated using a vibrating table which uses a specific experimental setup to analyse the ground response and double-porosity soil characteristics. Since the first half of the last century, there has been significant progress in understanding the effects of vibration on the strength and deformation properties of soils [21-22].

A number of different experiments with vibration application have been conducted on cohesive and cohesion-less soils that generated valuable data that has led to the discovery of important conclusions [23-24]. Increase in acceleration will decrease the internal friction approaching to a limit value which depends on the properties of a soil. Double-porosity soil is used to characterize soils that consist of two specific sub-regions and display different characteristics of pore sizes and hydraulic properties. It also displays bimodal pore-size distribution due to the condition of inter-aggregate and 
intra-aggregate pores in aggregated soil, which can be found in compacted soil and also in agricultural topsoil's [8-9].

Meanwhile, ${ }^{26}$ had conducted a one-dimensional drying and consolidation experiments on aggregated kaolin soil. It indicated that the aggregated soil response approached on non-aggregated soil in terms of fluid retention and compressibility when applied above a certain vertical stress. In addition, ${ }^{5}$ had performed a cracked soil network in experimental to estimate the flow rate. The researchers had found that the flow rate through the cracked soil network is bigger when compared to soil matrix for seepage rate.

As mentioned by ${ }^{8}$, there is still a gap in open literature on investigations via experiment on immiscible fluid movement in double-porosity soils. Therefore, to achieve the aim of this study, based on the previous literature, the objectives of this study are (i) to investigate the acceleration response on non-repeated for double-porosity soil with different moisture content, and (ii) to determine inter-aggregate and intra-aggregate on vibrated double-porosity soil characteristics.

\section{Materials and methods}

In this study, the laboratory experiment setup and procedures consisting of the physical apparatus, soil samples and aggregation are briefly discussed in subsequent sections.

\subsection{Soil sample preparation}

The soil that was used for this study as the doubleporosity were laterite soil samples. The samples were collected from a field situated at the School of Electrical, Faculty of Engineering, Universiti Teknologi Malaysia. The laterite soil properties were tested based on British Standard BS1377-2:1990 then the soil characteristics were obtained on liquid limit $=66 \%$, plastic limit $=33 \%$, plasticity index $=33 \%$ and particle density $=$ $2.74 \mathrm{Mg} / \mathrm{m} 3$. Based on the Unified Soil Classification System (USCS), the soil was classified as clay with high plasticity (ML). The method expressed in ${ }^{26}$ was used to prepare the aggregated soil sample. The soil sample preparation used different moisture content such as 30\% and $34 \%$. Thus, the dried laterite soil was mixed with $30 \%$ and $34 \%$ of moisture content for sample 1 and sample 2, respectively. The samples were kept in a cool environment for a minimum of 24 hours. Then the mixed sample was cured and kept in a re-sealable plastic bag for the purpose of preventing the moisture content from being evaporated. Dried aggregate soil that passed the $2.36 \mathrm{~mm}$ sieve for both sample 1 and sample 2 were placed in a circular acrylic column and compressed until $100 \mathrm{~mm}$ height using a simple compression machine. The acrylic soil column was used to detect and monitor any changes that occurred to the area and soil inside the transparent circular column. The prepared soil samples are shown in Figure 2.

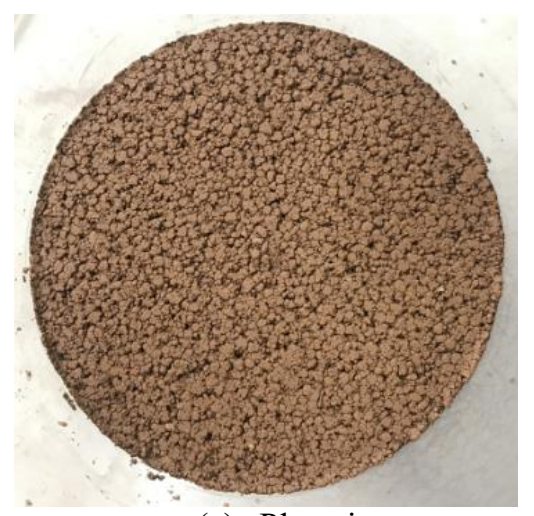

(a) Plan view

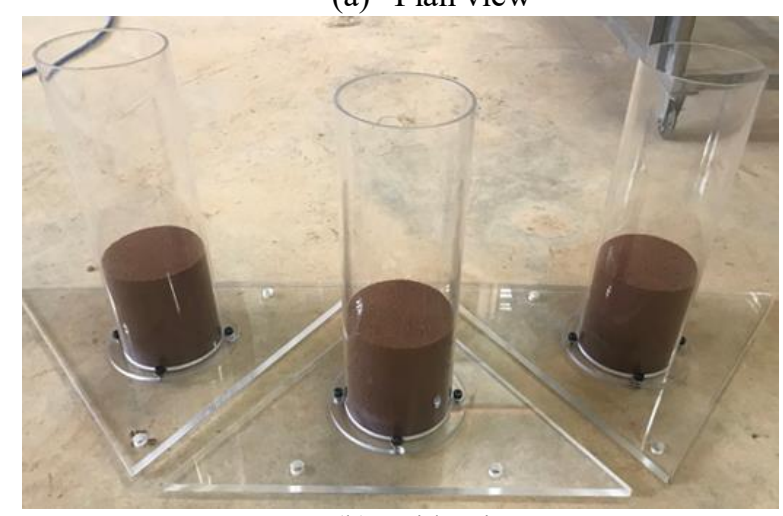

(b) Side view

Fig. 2. Prepared soil sample

\subsection{Laboratory experiment setup and procedure}

The experiments were executed in an acrylic soil column that has a sealed base and designed with the dimensions of $300 \mathrm{~mm}$ high $\times 100 \mathrm{~mm}$ outer and $94 \mathrm{~mm}$ inner diameter. A vibrating table was used to vibrate the soil samples using different vibration amplitudes in order to test the deformation process. The acrylic soil column was placed on the vibratory table and aligned securely by bolt and nut to avoid movement or bouncing of the acrylic soil column. It is important to have the best observation of the phenomena that occurs inside the whole area of the acrylic soil column. During the vibration process, PTA and PSSA for all the samples were recorded and the inter-aggregate and intraaggregate was observed. The vibrating table and acrylic soil column with the inclusion of a triangular base plate was developed to accomplish an economic and effective concept. Figure 3(a) shows the view of the 3D laboratory setup. The experimental procedure was arranged as shown in Figure 3(a) and 3(b). 


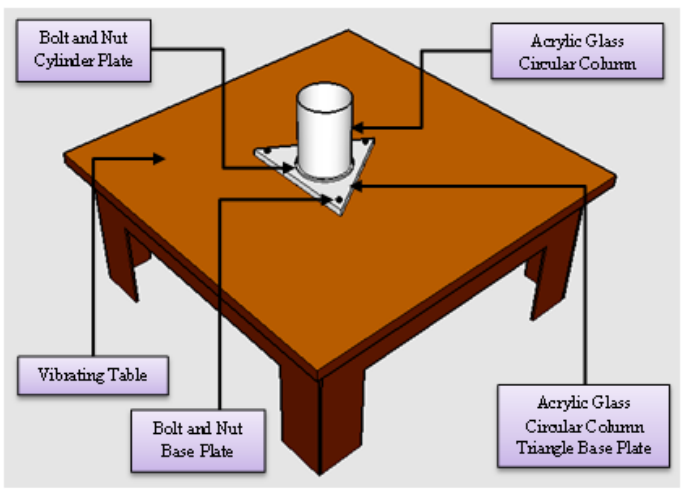

(a) 3D Laboratory experimental setup

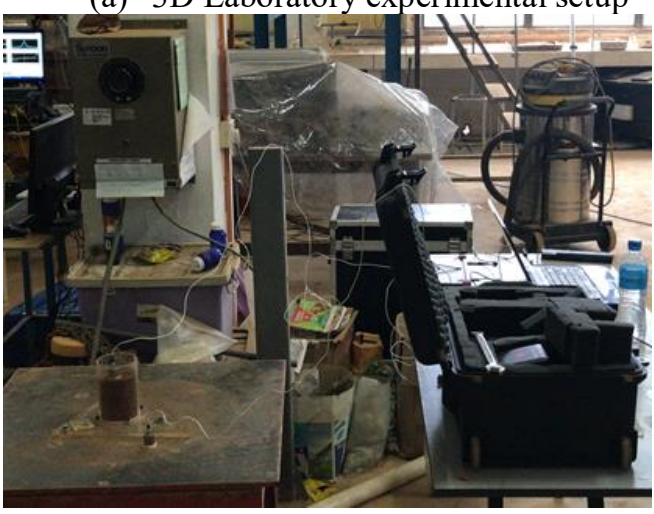

(b) Actual experimental setup

Fig. 3. Experimental setup

\section{Results and analysis}

\subsection{Acceleration response on non-repeated vibration for double-porosity soil}

Based on the objectives of the study, the results obtained are as presented below. The results for PSSA and PTA for both samples as well as the calibrated vibrating table amplitude are shown in Table 1.

Table 1. Calibrated non-repeated vibration and acceleration responses, PSSA and PTA results.

\begin{tabular}{|c|c|c|}
\hline \multirow{2}{*}{$\begin{array}{c}\text { Calibrated } \\
\text { Vibratory } \\
\begin{array}{c}\text { Table } \\
\text { Amplitude (A) }\end{array}\end{array}$} & \multicolumn{2}{|c|}{ Acceleration Response (A) } \\
\cline { 2 - 3 } & $\begin{array}{c}\text { Sample 1 } \\
\text { (PSSA/PTA) }\end{array}$ & $\begin{array}{c}\text { Sample 2 } \\
\text { (PSSA/PTA) }\end{array}$ \\
\hline 1.240 & $1.47 / 1.16$ & $1.49 / 0.82$ \\
\hline 2.450 & $2.48 / 1.91$ & $2.6 / 1.33$ \\
\hline 2.690 & $2.74 / 2.44$ & $3.36 / 1.72$ \\
\hline 3.320 & $3.35 / 3.00$ & $3.78 / 1.99$ \\
\hline 3.610 & $3.59 / 3.23$ & $4.22 / 2.37$ \\
\hline 3.990 & $4.06 / 3.47$ & $4.08 / 2.59$ \\
\hline 4.220 & $5.67 / 3.61$ & $4.31 / 2.76$ \\
\hline
\end{tabular}

As shown in Table 1, the vibrating table control panel amplitude as mentioned earlier was differentiated from the calibrated vibrating table indicator. Therefore, the calibrated amplitude value was used as the vibrating table indicator since the amplitude was obtained from the calibrated seismic accelerometers with high sensitivity. Based on Table 1 and the observations made during the experiment, sample 1 and sample 2 started to amplify due to shaking at the amplitude of $2.45 \mathrm{~A}$, where the values of PSSA/PTA (2.48/1.91) and (2.6/1.33) increased the gap between PSSA and PTA. Sample 2 experienced a larger amplification shaking, where the value of PTA (1.33) was lower than the value of PSSA (2.6). This meant that the shaking of the surface was higher than the shaking of the ground. Hence, in order to analyse the acceleration response, it was necessary to produce the graphs of amplitude versus PTA and PSSA values based on the result obtained in Table 1 .

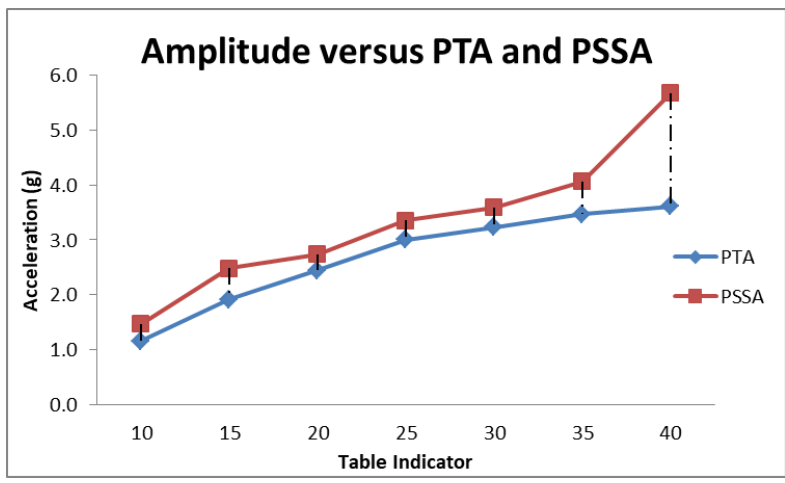

Fig. 4. Non-repeated vibration on amplitude versus PTA and PSSA for sample 1

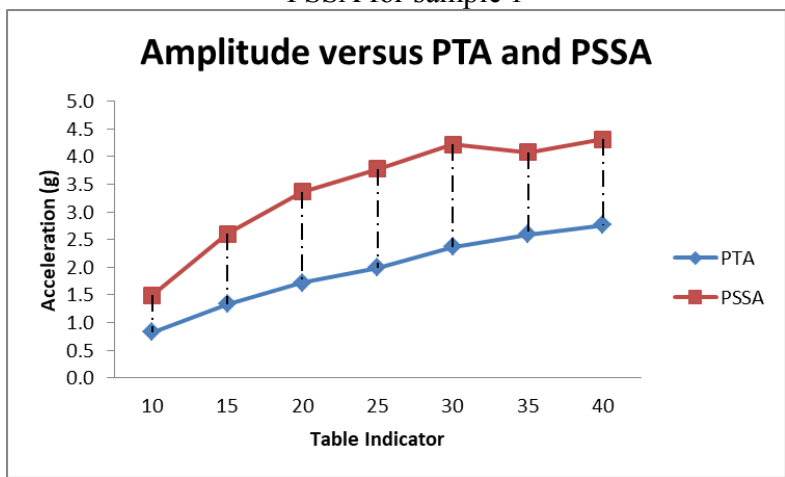

Fig. 5. Non-repeated vibration on amplitude versus PTA and PSSA for sample 2

\subsection{Validation of the double-porosity soil characteristics}

The double-porosity soil characteristics were validated using Scan electron Microscopy (SEM). The result of depth zoomed-in image of vibrated double-porosity, $30 \%$ and $34 \%$ moisture content at 180 -fold, 1000 -fold and 3000-fold magnification is shown in Figure 6. The results of SEM test at 180-fold magnification shows cracks and fracture on the soil sample surface, while results of the FESEM test at 1000-fold magnification displayed the inter-aggregate pores. The FESEM test at 180 -fold magnification has also exposed that the interaggregate pores and individual laterite granules split up among themselves. Further magnification of both soil samples up to 3000 -fold indicated the presence of intraaggregate pores. Through the SEM test, it was clearly shown that the vibrated double-porosity soil structure was verified with the deformable characteristics of aggregate pores, inter-aggregate pores and intraaggregate pores that created the double-porosity 
formation. From the SEM test results, soil sample 2 has more porosity compared to sample 1 . All samples have a similarity whereby the soil is coated with a layer of liquid that causes a shining image when viewed by SEM close up image. Both samples also have a coarse granule structure and displayed the characters of soil liquidity. Therefore, the vibrated double-porosity characteristics with multi-porosity were expected to contribute to the speed of liquid penetration and migration.

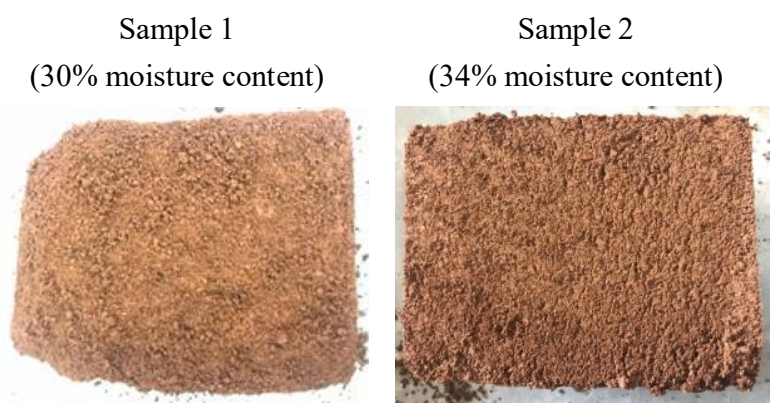

Original soil sample

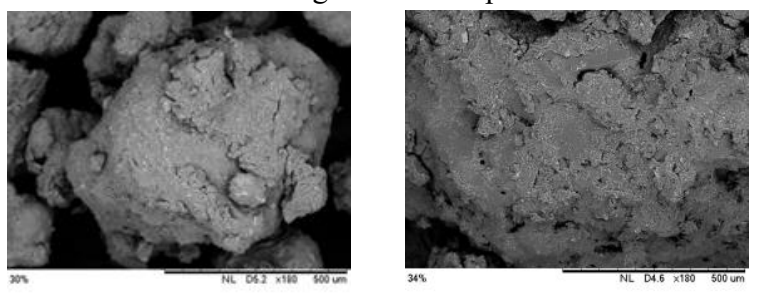

180-fold magnification

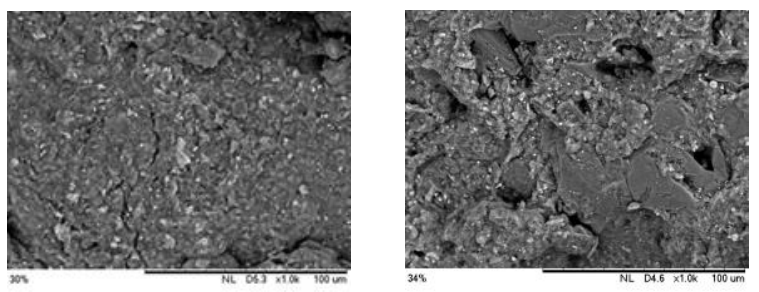

1000-fold magnification
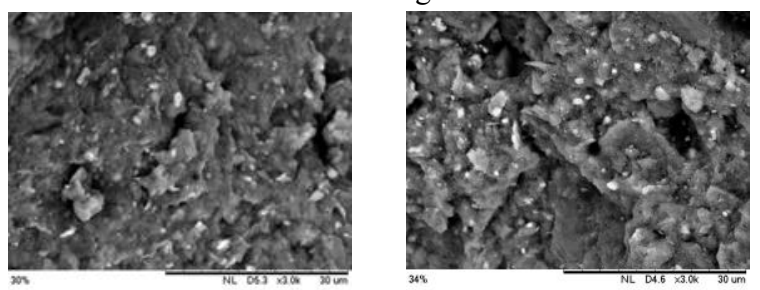

3000-fold magnification

Fig. 6. SEM magnified image of double-porosity with 180 , 1000 and 3000 -fold magnification.

\section{Conclusion}

A physical laboratory experiment on deformable doubleporosity soil with different moisture content under nonrepeated vibration effect was conducted. The experiments have successfully obtained the result of acceleration responses through vibrating. From the scanning electron microscopy (SEM) test that was carried out, the deformable double-porosity soil was verified and confirmed inter-aggregated and intra- aggregated in soil characteristics. Sample 2 has shown bigger amplification shaking due to the weakened soil structure compared to sample 1, while sample 1 has smaller amplification shaking because soil sample 1 had a stiff soil structure. Based on the result obtained from the SEM test, all samples reveal inter and intra aggregate soil. Since the soil samples hold the characteristics of multi-porosity, therefore the soil has been identified as problematic double-porosity soil. It also indicates that there is a bigger dis-amplification process on nonrepeated double-porosity soil. Moreover, non-repeated vibrated double-porosity soil has different behaviour characteristics on permeability and wettability compared to a non-repeated double-porosity soil based on the experiment performed by ${ }^{22}$ and also by ${ }^{10}$ that excluded the vibration effect. The effect of moisture content percentage on the laterite soil granule was found to be significant as it proved that seismic acceleration response values were different for those samples. Therefore, non-repeated vibration double-porosity soil has characteristics of soil structure rearrangement and change in existing moisture content. In addition, high permeability value was expected to be an influential factor in the movement of the fluid in the subsurface system.

This study was supported by the Research Management Centre (RMC), Universiti Teknologi Malaysia under Research University Grant - Tier 1 20H53. The authors would also like to thank their respective Universities, Geotechnical Laboratory, Hydraulic Laboratory and Engineering Seismology and Earthquake Engineering Research Group (eSEER), School of Civil, Faculty of Engineering, Universiti Teknologi Malaysia for cooperation of this research. The authors also express their deepest appreciation to UTMLead and Kings' Scholarship for supporting this research study and all those involved either directly or indirectly.

\section{References}

1. Muguntan Vanar, Ruben Sario, Lee S. Strong earthquake strikes Sabah. The Star Online. https://www.thestar.com.my/news/nation/2015/0 6/05/sabah-quake/. Published June 5, 2015.

2. Sario R. Sabah shaken by quake off Philippines. The Star Online.

http://www.thestar.com.my/news/nation/2017/01 /10/sabah-shaken-by-quake/. Published January 10, 2017.

3. Siyahi B, Cetin KO, Unutmaz B, et al. The Effects of Site and Soil Conditions To the Earthquake Damage : Oct, 232011 Van-Tabanl Earthquake ( $\mathrm{M} \mathrm{w}=7.2$ ). 2012.

4. Fredlund DG, Houston SL, Nguyen Q, Fredlund MD. Moisture Movement Through Cracked Clay Soil Profiles. Geotech Geol Eng. 2010;28(6):865-888. doi:10.1007/s10706-0109349-x

5. Krisnanto S, Rahardjo H, Fredlund DG, Leong EC. Mapping of cracked soils and lateral water flow characteristics through a network of cracks. Eng Geol. 2014;172:12-25. 
doi:10.1016/j.enggeo.2014.01.002

6. Carminati A, Kaestner A, Lehmann P, Flühler H. Unsaturated water flow across soil aggregate contacts. Adv Water Resour. 2008;31(9):12211232. doi:10.1016/j.advwatres.2008.01.008

7. Taslagyan KA, Chan DH, Morgenstern NR. Effect of vibration on the critical state of dry granular soils. Granul Matter. 2015;17(6):687702. doi:10.1007/s10035-015-0589-6

8. Figure S. No Title No Title_2015. 2012;(c). doi:10.15713/ins.mmj.3

9. Li X, Zhang LM. Characterization of dualstructure pore-size distribution of soil. Can Geotech J. 2009;46(2):129-141. doi:10.1139/T08-110

10. El-Zein A, Carter JP, Airey DW. Threedimensional finite elements for the analysis of soil contamination using a multiple-porosity approach. Int J Numer Anal Methods Geomech. 2006;30(7):577-597. doi:10.1002/nag.491

11. Lewandowska J, Szymkiewicz A, Gorczewska $\mathrm{W}$, Vauclin M. Infiltration in a double-porosity medium: Experiments and comparison with a theoretical model. Water Resour Res. 2005;41(2):1-14. doi:10.1029/2004WR003504

12. Lakeland DL, Rechenmacher A, Ghanem R. Towards a complete model of soil liquefaction: The importance of fluid flow and grain motion. Proc R Soc A Math Phys Eng Sci. 2014;470(2165). doi:10.1098/rspa.2013.0453

13. Barcelona MJ, Kim M, Masciopinto C, Mantia R La. A Gypsum-Barrier Design to Stop Seawater Intrusion in a Fractured Aquifer at Salento ( Southern Italy ). 2006:263-272.

14. Valliappan S, Khalili-Naghadeh N. Flow through Fissured Porous Media with Deformable Matrix. Int J Numer Methods Eng. 1990;29(August 1989):1079-1094.

15. Luckhaus S, Mikeli A. Bourgeat, luckhaus:,. 1996;27(6):1520-1543.

16. Pao WKS, Lewis RW. Three-dimensional finite element simulation of three-phase flow in a deforming fissured reservoir. Comput Methods Appl Mech Eng. 2002;191(23-24):2631-2659. doi:10.1016/S0045-7825(01)00420-0

17. Ryzhik V. Spreading of a NAPL lens in a double-porosity medium. Comput Geosci. 2007;11(1):1-8. doi:10.1007/s10596-006-9040-8

18. Kamaruddin SA, Sulaiman WNA, Rahman NA, Zakaria MP, Mustaffar M, Sa`ari R. A review hydrocarbon migration.pdf. 2011:191-214.

19. Kamaruddin SA, Sulaiman WNA, Zakaria MP, Othman R, Rahman NA. Laboratory simulation of LNAPL spills and remediation in unsaturated porous media using the image analysis technique: A review. 2011 Natl Postgrad Conf. 2011:1-7. doi:10.1109/NatPC.2011.6136348

20. Sa ari R, Rahman NA, Latif Abdul NH, et al. Application Of Digital Image Processing Technique In Monitoring LNAPL Migration In Double Porosity Soil Column. J Teknol. 2015;3(72):23-29. doi:10.11113/jt.v72.4018
21. Foong LK, Rahman NA, Ramli MZ. A Laboratory Study of Vibration Effect for Deformable Double-Porosity Soil with Different Moisture Content. 2016;222(3):207-222.

22. Housner GW. Geotechnical Problems of Destructive Earthquakes. Géotechnique. 1954;4(4):153-162.

doi:10.1680/geot.1954.4.4.153

23. Ndoj A, Shkodrani N, Hajdari V. LiquefactionInduced Ground Deformations Evaluation Based on Cone Penetration Tests ( CPT ). World J Eng Technol. 2014;(November):249-259.

24. Meehan CL, Brandon TL, Duncan JM. Measuring "fast" shear strengths along slickensided surfaces in the Bromhead ring shear. Geotech Test J. 2008;31(3):239-242. doi:10.1520/GTJ101325

25. Wartman J, Seed RB, Bray JD. Shaking Table Modeling of Seismically Induced Deformations in Slopes. J Geotech Geoenvironmental Eng. 2005;131(5):610-622. doi:10.1061/(ASCE)10900241(2005)131:5(610)

26. Bagherieh AR, Khalili N, Habibagahi G, Ghahramani A. Drying response and effective stress in a double porosity aggregated soil. Eng Geol. 2009;105(1-2):44-50. doi:10.1016/j.enggeo.2008.12.009 